\title{
Guerra y tragedia: el sentido dramático de la párodos del Agamenón de Esquilo ${ }^{1}$
}

War and tragedy: the dramatic sense of the parodos of Agamemnon by Aeschylus

David García Pérez

Centro de Estudios Clásicos, Universidad Nacional

Autónoma de México, México

hyperion0z@yahoo.com

(iD http://orcid.org/0000-0001-5312-2544

\section{RESUMEN:}

Tomando como punto de partida la lectura de la guerra de Troya que Yannis Ritsos plantea en el inicio de su poema Agamenón, se propone en este artículo un análisis de la párodos del poema homónimo de Esquilo a través del sentido que cobra lo trágico de acuerdo con el destino de los Atridas, específicamente de Agamenón, su proyección simbólica en el conflicto con los troyanos, el sacrificio de Ifigenia y el dolor que implica el aprendizaje de los avatares del destino.

Palabras Clave: Aprendizaje, Esquilo, Agamenón, Guerra, Párodos.

\section{Abstract:}

Taking as a motive the reading of the Trojan War that Yannis Ritsos raises at the beginning of his poem Agamemnon, this paper proposes an analysis of the parodos of the homonymous poem by Aeschylus, through the sense that the tragedy charges from the fate of the Atridas, specifically of Agamemnon, the sacrifice of Iphigenia, its symbolic projection in the conflict with the Trojans and the pain involved in learning the avatars of destiny.

KeYwords: Aeschylus, Agamemnon, Knowledge, Parodos, War.

La parte siguiente al proemio de su poema Agamenón, cuando inicia específicamente el monólogo del rey argivo, los primeros versos de Yannis Ritsos son una serie de preguntas dirigidas a Clitemnestra que develan de inmediato la necedad de la guerra de Troya que, una vez finalizada, devuelve a Agamenón a la realidad en el tiempo de paz, en la que el absurdo se impone como respuesta a la empresa bélica, dada la situación trágica en la que aquél se ve inmerso. Y absurdo también porque nunca hubo armonía en el palacio del Atrida, pues se enfrentó a su verdadera tragedia al regresar a su tierra. El rey ha vuelto y lo que encuentra es, como se esperaría luego de la victoria, a su pueblo que lo celebra con gritos, aplausos y aclamaciones. La escena resulta contradictoria para quien ha pasado fuera de su casa por más de diez años, dirigiendo la confederación aquea hasta la caída de Troya. Se intuye a partir de las palabras iniciales de Agamenón la dilatada distancia que media entre el que ha vivido los horrores de la guerra y quienes han estado a la espera en Argos, junto con la reina, pues las situaciones efectivas de una y de otra parte es lo que dimensiona el sentido de la guerra y las posibles consecuencias que supone el triunfo. La celebración del pueblo argivo es la respuesta natural a un largo período de zozobra en la que ambos bandos, aqueos y troyanos, han tenido que sobrellevar el conflicto bélico y dar sepultura a sus muertos. Estas acciones y aquellas que dibujan la profundidad terrible que implica una larga y dolorosa contienda es lo que lleva a definir, además, el punto final como una especie de vacío que hace pensar a Ritsos, poeta soldado, en una pregunta imperiosa: ¿y ahora, qué? ${ }^{2}$ El recibimiento ruidoso de los argivos choca frontalmente con la sensibilidad del rey vencedor que, sin embargo, se siente derrotado por lo que ha visto, lo que ha vivido y lo que contra su voluntad ha tenido que llevar a cabo para volver triunfante a su palacio. Quizá por ello las preguntas referidas adquieren la profunda dimensión de vacío en el sujeto que ha atravesado los avatares de la guerra y, ante la victoria, se coloca en el lugar del otro, dirigiendo estas palabras a Clitemnestra:

Recepción: 30 de diciembre de 2019 | Aceptación: 26 de mayo de 2020 | Publicación: 12 de junio de 2020

Cita sugerida: García Pérez, D. (2020). Guerra y tragedia: el sentido dramático de la párodos del Agamenón de Esquilo. Synthesis, 27(1), e075. https://doi.org/10.24215/1851779Xe075 


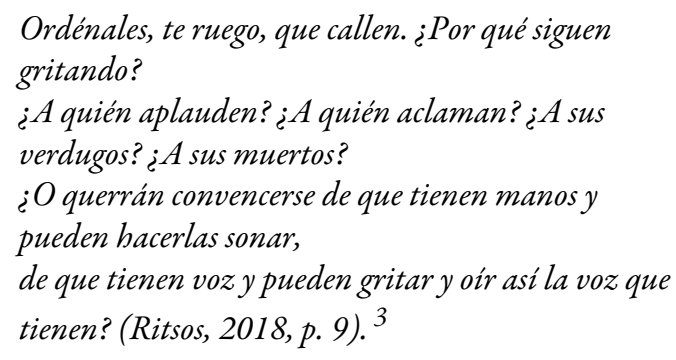

Esta imagen del poema de Ritsos es, a nuestro juicio, una clara relectura de la parte de la párodos del Agamenón de Esquilo que atiende el motivo de la guerra y de lo trágico. Lo que este poeta resuelve como cuestionamiento del sentido de la guerra en unos cuantos versos, Esquilo lo desmenuza en una extensa párodos de 217 versos, la más dilatada entre las tragedias que se conocen del antiguo teatro ateniense, ${ }^{4}$ pues su función es la de acotar brevemente el contexto de los eventos que se representan en las tres piezas que componen la Orestiada, es decir, la guerra de Troya como antecedente en la cauda de desgracias que acompañan a los Atridas desde tiempos en los que se pierde la memoria, ${ }^{5}$ el sacrificio ineludible de Ifigenia y la consecuente venganza de Clitemnestra al asumirse como Erinia vengadora de su hija, ${ }^{6}$ y en ese mismo rumbo la orientación hacia la significación de lo trágico que culmina con la absolución de Orestes, matricida confeso, en el tribunal del Areópago. La alusión simbólica de los tres primeros tópicos referidos por el Coro en la párodos evidencia su función como sujeto de memoria, de juicio y de enseñanza, por lo que el estar conformado por ancianos imprime una mayor verosimilitud al contenido de esta parte del Agamenón.

En efecto, el Coro está compuesto de ancianos argivos que son descritos como carne vieja y como niños que se sirven del bastón para caminar. ${ }^{7}$ La guerra ha durado diez años, pero las imágenes con las que los coreutas se describen a sí mismos profundizan la sensación de que el tiempo transcurrido ha sido más prolongado, de manera que la orientación metafórica que coloca el ímpetu juvenil a través de la imagen "tuétano de la

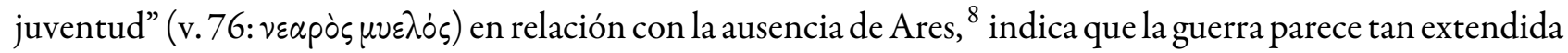
como lo que los ancianos han vivido hasta ese momento. En otras palabras, la descripción corresponde a la guerra que se ha hecho vieja, tanto que la llegada del rey, a pesar del alborozo que causa, es también la bienvenida a un hombre acosado por los años y las desgracias que se han fraguado durante este tiempo, tal como lo advierte el Guardia en el prólogo. Al perfil del anciano sin vigor guerrero, se suma aquella imagen de prosapia épica y lírica: la índole del follaje marchito o caído como referente de la edad. ${ }^{9}$ Los ancianos son como árboles cuyo verdor se ha marchitado, descripción que guarda una serie de contenidos alegóricos, el más evidente es el de señalar la decadencia del vigor, sobre todo porque con ello se traza una referencia emblemática con la guerra. No obstante, este Coro de ancianos se define también, versos más adelante (vv. 255-257), como la última defensa de la tierra Apia, es decir, el baluarte que resta luego de la guerra como salvaguardia de Argos. La imagen es contradictoria: la vejez es un regreso a la niñez en cuanto a la eficacia física, pero el transcurso de la vida hace del anciano un ser corporalmente más desprovisto que el infante, de manera que ante los hechos trágicos que están por ocurrir el Coro es la barrera de contención, lo que resulta paradójico. Sin embargo, como veremos más adelante, se puede equilibrar tal contradicción, si se atiende el contenido pedagógico presente en la sentencia $\pi \dot{\alpha} \theta \varepsilon \iota \mu \dot{\alpha} \theta \circ$ s: la sabiduría aprendida a través del dolor sólo puede ser cualidad de un ser humano que ya ha recorrido parte considerable de su destino. Y es natural que la sabiduría del $\pi \dot{\alpha} \theta \varepsilon \iota \mu \dot{\alpha} \theta \circ$ s sea una clara prerrogativa del anciano.

En las guerras prolongadas es común que los hombres jóvenes sean los primeros en abandonar los pueblos, donde sólo van quedando los ancianos, los niños y las mujeres. En este sentido resulta sintomático que sea un Coro de ancianos el que acompaña el desarrollo del Agamenón - y que el Coro de Las Coéforas esté formado por doncellas y el de Las Euménides por deidades metamórficas: primero Erinias, luego Euménides -, y que haya referencia en dos ocasiones en esta parte a la figura del niño ( $\mathrm{Ag}$. v. 75 y 81). A causa de 
su decadencia, el viejo se describe como si fuera un infante, con la desventaja de que se tiene que apoyar en un bastón, su tercer pie para poder caminar. La conjunción de estas imágenes revela, a nuestro juicio, una comprensión particularmente esquilea de la guerra: el paso del tiempo real intensificado por el retrato deprimido del anciano conduce a pensar en un conflicto sin razón, agotado por el mismo correr de los años: la guerra deviene en una anciana, cuando se prolonga demasiado. Pero, al mismo tiempo, esta composición prepara la apertura de la tragedia en sí, la puesta en escena de la desgracia que conduce al matricidio cometido por Orestes. La guerra es tragedia que no cesa con la caída de Troya; antes bien, sólo parece dar una tregua para manifestarse álgidamente al interior de la casa de los Atridas: el dolor transita de la confrontación entre los dos pueblos a la resolución de añejas querellas que únicamente pueden ser dirimidas de origen en el marco familiar, que es lo que ocurre en el Agamenón, pero que en Las Euménides se dirime en el plano público con el juicio de Orestes en el Areópago. ${ }^{10}$ Dicho de otro modo, Esquilo cuenta de manera resumida y alegórica en la párodos algunos sucesos de la guerra de Troya como preámbulo de la tragedia que involucra a la descendencia de Agamenón, misma que se ha incubado desde hace mucho tiempo, pero que, a diferencia de la guerra, no olvida su necesario derramamiento de sangre.

Entonces, con la conjetura de que el Coro del Agamenón expresa un sentido peculiar de la guerra, se colige que Esquilo estructuró las premisas de la Orestiada comparando la guerra de Troya con su momento histórico, es decir, con la experiencia del conflicto bélico que lo marcó como ciudadano, combatiente y poeta en el conflicto contra los persas. Y este sentimiento lo transmite a través de imágenes que sugieren tal empalme entre una visión mítica y otra histórica sobre el significado de la guerra por medio de las palabras sabias y de las imágenes con un alto contenido bélico que corresponden naturalmente a la narración de los ancianos, portadores de experiencia. Hay una inquietud por la larga duración de los combates y por la zozobra que vive Argos a causa de este mismo motivo. Han sido diez años en los que el pueblo de Agamenón no ha tenido en sí un rey que rija sus destinos, y en este tiempo ha madurado la venganza de Clitemnestra para vengar la muerte de Ifigenia, con la complicidad de Egisto, quien también vería en el acto criminal la venganza contra Atreo a través de sus descendientes, específicamente en el rey argivo. ${ }^{11}$ Las últimas palabras del Guardia, en el prólogo del Agamenón dejan entrever la maquinación de los amantes y las nefandas acciones que han ocurrido durante la ausencia del rey:

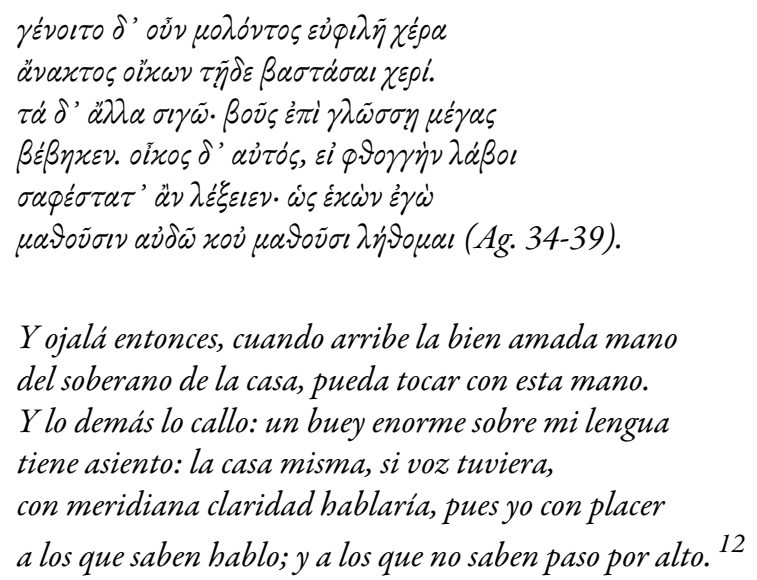

El arribo de Agamenón a su palacio marca el inicio de las acciones trágicas en sí, de acuerdo con el plan dramático de Esquilo en cuanto a la disposición de cada uno de los personajes de la trilogía. Así, el sacrificio de Ifigenia y las cuestiones de la guerra contra Troya sustentan las proposiciones que desencadenarán los sucesos terribles al interior de la familia: la guerra es una tragedia compartida, a pesar de las causas particulares que la motivaron, pero el verdadero sentido de lo trágico se particulariza en el peligro de disolución que corre la familia regente y, por extensión, de la misma Argos. Por ello las palabras del Guardia que anteceden el inicio de la párodos están marcadas por el simbolismo del silencio que cae como un pesado buey sobre la lengua de este 
personaje. Es como decir que todos saben lo que sucedido, pero nadie dirá nada. El destino seguirá su curso. Toda Argos sabe lo que ha ocurrido durante diez años, menos el rey que regresa para morir derrotado por un destino que desde la lectura de Ritsos se puede leer como un absurdo. Si traemos a colación la idea de este poeta griego con la cual guiamos la interpretación propuesta, se puede entender la situación contradictoria que atraviesa Agamenón y que lo lleva a un punto muerto frente a la decisión fatal tomada por Clitemnestra y alimentada por Egisto.

Uno de los motivos que se repite en la saga trágica de los Atridas desde los tiempos de Tántalo es el poder dado a los personajes desde la misma voluntad divina y que tiene que ser retribuido por explicación del destino a través de la acción trágica. Tal poder adquiere un sentido peculiar en la tragedia esquilea con el término $\tau \varkappa \eta_{\eta}:{ }^{13}$ el poder conferido a los Atridas los caracteriza esencialmente frente al resto de los mortales; ${ }^{14}$ se trata de una honra dada por los dioses, pero que lleva implícita un sentido trágico. A manera de un regalo dado por las deidades, la $\tau \iota \mu$ il leva oculto el padecimiento de lo trágico, que en el caso de Agamenón, se revela en el sacrificio inexcusable que debe realizar con su propia hija y el cobro de la sangre filial derramada por parte de Clitemnestra. De este modo se equilibra el poder absoluto, entregado a los Atridas por el mismo Zeus (v. 43-44), con la desgracia familiar —íntima, de puertas adentro en su origen - que implica el destino final del rey y de su poder.

La $\tau \mu \eta \dot{y}$ es, entonces, el poder que el Cronida confirió a los Atridas, y las consecuencias del ejercicio de esta cualidad es lo que lleva a la derrota de Agamenón, a pesar de haber triunfado en Troya. Esta situación cobra forma con dos imágenes alegóricas alusivas a las aves: en primer lugar, Agamenón y Menelao son comparados con buitres que pelean por la salvación de sus hijos. ${ }^{15}$ La disposición de los reyes es semejante al modo en el que estas aves de rapiña revolotean sobre su presa - Troya - y su canto es similar al grito que llama a la guerra. De acuerdo con West, esta alegoría cobra sentido si se entiende que lo que se busca en el desarrollo de la trilogía es hacer justicia divina, pues Apolo, Pan o Zeus serían quienes motivan la guerra contra Troya. ${ }^{16}$ El objetivo de los Atridas-buitres es la salvación de sus hijos, aunque paradójicamente eso implique el perder el interés por los polluelos a causa de la misma misión bélica. En otras palabras, el combate tiene lugar en la costa troyana, lejos de Argos, pues los reyes-buitre han ido a luchar a causa de Helena, seducida en el palacio de Menelao por Paris, quien violó de este modo la disposición religiosa que se debe a Zeus hospitalario. ${ }^{17}$ Hay, pues, una paradoja en el proceder de los Atridas, porque, por una parte, se disponen a devorar a Troya, como pasto de aves de rapiña, pero, por otro lado, esta acción implica el abandono de los suyos, de su patria. El olvido — semejante a la nostalgia de Odiseo- es otro rostro de la soberbia (býbris), el motor de toda tragedia. Esta oposición expresa quizá la visión particular de Esquilo sobre el sentido de la guerra, pues la justificación sobre el castigo contra Paris por la violación de hospitalidad, quien obró así una grave ofensa contra el mismo Zeus (vv. 40-59), choca frontalmente con la imagen de este dios colocado en medio de la confrontación entre aqueos y troyanos, es decir, vigilando que la balanza no se incline durante mucho tiempo para ningún bando (vv. 60-67). Como se puede observar, una idea sigue de inmediato a la otra, lo que quizá hubiera creado cierta curiosidad e, incluso, contrariedad en el espectador al escuchar que el Cronida es quien acompañó a los aqueos a la guerra y es él mismo el que "quebrada/ el asta de la lanza, impone a dánaos/ y a troyanos por igual" (vv. 65-67).

En segundo lugar, se despliega una alegoría de la guerra emprendida por los Atridas a través del portento de dos águilas, una negra y otra blanca, en alusión al poder bélico de los reyes argivos, quienes finalmente derrotaron Troya, simbolizada aquí como una liebre preñada; ésta última es la presa de las aves de rapiña —los reyes argivos que truecan de buitres en águilas-, cuyo fruto es devorado por éstas, es decir, el pueblo troyano es socavado de raíz, desde el mismo vientre de la ciudad de Príamo para que no hubiera sobrevivientes de la debacle. Ahora bien, no obstante que el vuelo de las aves reales tiene como sentido una acción propiciatoria, las tres partes en las que se divide esta sección del Coro, compuesta por la estrofa $1^{\text {a }}$, su correspondiente

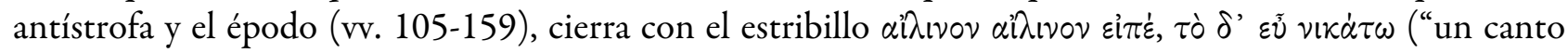


fúnebre, fúnebre, entona, pero que el triunfo sea bueno"), ${ }^{18}$ que matiza fuertemente el triunfo de la caza de la liebre. En efecto, la interpretación de Calcas explica lo contradictorio de este verso, pues el triunfo de los Atridas es visto en la cacería de las águilas como la caída de Troya, pero al mismo tiempo la sombra de la desgracia pesa sobre los triunfadores al señalar que Ártemis es contraria a las águilas que cazan y se dan un festín con la liebre: el triunfo resulta bueno, pero el canto con el que se celebra es fúnebre. ${ }^{19} \mathrm{Y}$ es aquí donde se halla la referencia a Ifigenia, pues la victoria de los argivos dependía del sacrificio que Agamenón debía llevar a cabo, ofreciendo a su hija para calmar la ira de Ártemis, quien se hallaba irritada contra el Atrida porque había cazado una cierva en un espacio sagrado y, además, su soberbia lo llevó a afirmar que era el mejor cazador, según se informa en otras fuentes, ${ }^{20}$ pues en la Orestiada no queda clara la reclamación y la petición de la diosa a Agamenón. ${ }^{21}$ Sin embargo, la muerte de la doncella es un tópico transcendente porque articula el rumbo de la guerra y las consecuencias de ésta: la suerte del rey argivo está echada desde el momento en el que se ve compelido por Ártemis a ofrecer como ofrenda a Ifigenia. Se trata, además, de un ritual en cuanto que es la repetición del mismo patrón de sacrificio que se origina con Tántalo y el guiso hecho con su propio hijo, Pélope, para ofrecerlo a los dioses: la hija de Agamenón deviene, paradójicamente, como un animal cazado para sacrificio de Ártemis, por lo que se trata de una acción fuera de la norma, no comestible —al igual que el expiación preparada con el cuerpo de Pélope- y una discordia mortal para la misma familia (vv. 150-152).

Es posible también, entonces, que el fruto de la liebre preñada tenga una implicación simbólica que refiere al mal oculto que las águilas devoran sin saberlo. El triunfo de los Atridas es como un banquete que inmediatamente tiene efectos nocivos. Como hemos sostenido, la $\tau \iota \mu \dot{~ e s ~ u n ~ d o n ~ d e ~ l o s ~ d i o s e s ~ q u e ~ o c u l t a ~ e l ~}$ efecto pernicioso que sólo se hace visible cuando sus efectos dañinos son ya irreversibles. En este tenor, el canto del Coro refiere un antecedente de la misma guerra y de los hechos más recientes - los que se están contando en el desarrollo mismo de la tragedia, es decir, la vuelta de Agamenón-, por lo que es posible

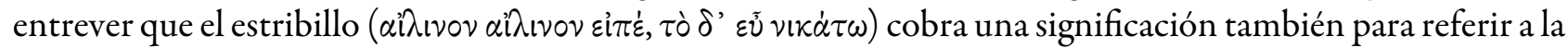
desgracia que está a punto de suceder con la llegada del rey. Las palabras del Coro (vv. 140-145), así como la mente de Calcas, apuntan claramente el pasado (los prolegómenos de la guerra) y, veladamente, el presente (la duda sobre si es cierta la noticia sobre el inminente arribo de Agamenón) y el futuro (la muerte de éste a manos de Clitemnestra y de Egisto).

La antístrofa $4^{a}$, la más extensa de la párodos (vv. 191-263), describe puntualmente el doloroso sitio de la flota aquea en Áulide y el obligado sacrificio que Agamenón debe realizar al ofrecer a Ifigenia, su hija, para que el bloqueo divino finalice y el ejército pueda continuar su marcha. Sólo de esta manera Ártemis permitiría que la tropa aquea partiera hacia su destino. ${ }^{22}$ Esta descripción se ajusta al tópico del conocimiento expuesto brevemente en la estrofa $4^{\text {a }}$ a través de la figura de Calcas: la revelación de la sabiduría es un duro aprendizaje para Agamenón y los suyos; peor será cuando la maldición de Ifigenia se torne realidad con el tiempo; por esta razón, el sacrificio de la doncella está dispuesto aquí como premisa para el posterior actuar de Clitemnestra contra su marido. En efecto, a modo de profecía, el Coro cesa de contar los antecedentes de la tragedia que está por ocurrir para que se cumpla la Justicia que da sabiduría a los sufrientes: "Justicia, en verdad, a los sufrientes el conocer les adjudica." 23

En efecto, el conocer sufriendo es una especie de máxima que aquí está estrechamente vinculada con la figura del Cronida, como se puede apreciar en este himno elevado en su honor. La alabanza a Zeus está conformada por la estrofa $2^{a}$ (vv. 160-166), que es una breve introducción en la que se invoca al Cronida para aligerar la pena del Coro; la antístrofa $2^{a}$ (vv. 160-166) enaltece el poder de esta divinidad al hacer un recuento simbólico de su origen: él es el tercer dios en la genealogía del panteón griego y se distingue de los anteriores dioses, Urano y Cronos, por su sabiduría. Este último tópico es el centro de este canto, pues la estrofa $3^{\text {a }}$ encomia el conocimiento de Zeus (vv. 176-183), mismo que se concede a los hombres con dolor ( $\pi \dot{\alpha} \theta \varepsilon l \mu \dot{\alpha} \theta \circ \varsigma)$ e, incluso, para los insensatos el conocer puede llegar con violencia divina. He aquí una de las máximas de la tragedia griega: ${ }^{24}$ un aspecto didáctico de este género poético es el de demostrar que los 
mortales sólo pueden tener conocimiento mediante el dolor, esto es, el proceso y el punto de llegada del saber es acerbo; el objeto del conocimiento abarca desde la simpleza de las cosas cotidianas hasta las cuestiones más trascendentales de la vida del hombre. Al mismo tiempo, $\pi \dot{\alpha} \theta \varepsilon \iota \mu \dot{\alpha} \theta \circ \varsigma$ sintetiza todo proceso trágico: la trilogía de Orestes se desenvuelve a través de un aprendizaje que sólo es posible a partir del sufrimiento, del dolor y sus consecuencias generadas por la cauda de errores de cada uno de los miembros de la familia de los Atridas. De acuerdo con este planteamiento, hay aquí un ejemplo concreto del pensamiento religioso de Esquilo: prácticamente la secuencia de los tópicos expuestos en la párodos tiene un compás de espera al momento en el que el poeta expone la trascedencia didáctica de la tragedia, pues todo conocimiento es un puro sufrir, teniendo en cuenta, además, que la sabiduría tiene a Zeus como principio y fin. Sin duda, está presente un eco del pensamiento hesiódico, en razón de que sólo la sabiduría recta pertenece a los dioses, específicamente al Cronida, y todo conocimiento posterior y fuera de él es torcido. ${ }^{25}$ De aquí se sigue que toda justicia humana es torcida y, por ello, sólo la intervención de los dioses puede acotar el mal hecho por el ser humano. Es por estas razones que cualquier acto llevado a cabo por el hombre mediante el cual se aprende algo deviene en un medio del sufrimiento y en una culminación en la que el sujeto padece lo trágico: la paradoja que define a Agamenón es la posesión de un poder $(\tau \iota \dot{\eta})$ dado por el mismo Zeus que lo lleva a vencer a los troyanos, pero cuya puesta en movimiento lo conduce al sacrificio forzoso de Ifigenia, que es vengada por Clitemnestra, una Erinia presta a asesinar a su propio marido. Siguiendo esta idea, Agamenón no tiene ninguna opción que pueda redimirlo o, mejor aún, salvarlo de la desgracia, pues se halla entre el deber del jefe supremo de la expedición contra Troya y el sacrificio de Ifigenia que le acarreará su propia aniquilación. Esta angustiosa situación trágica está bien acentuada en el momento en el que el rey argivo debe decidir llevar a cabo la muerte de su hija:

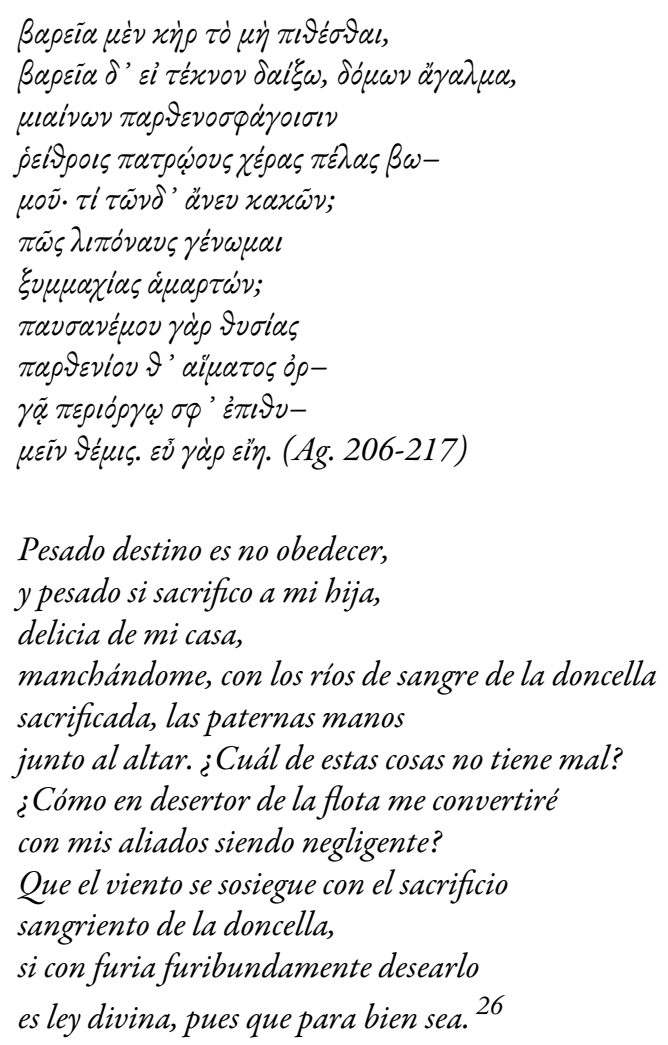

Ahora bien, aquí hay un problema más: el aprendizaje propio de la tragedia es dinámico, es decir, no es que exista previamente la sabiduría per se que conduce a los personajes a guiar de mejor manera su destino; el macanismo del $\pi \dot{\alpha} \theta \varepsilon \mathrm{\varepsilon l} \mu \dot{\alpha} \theta \circ \varsigma$, por el contrario, implica una serie de pasos que conducen a lo trágico irremediablemente, de tal modo que cuando se manifiesta el conocer es porque el dolor está ahí mismo, 
acompañando lo que el ser humano está aprendiendo. Y lo que se aprende ya existe cuando el individuo no puede remediar nada. ¿A quién sirve el conocimiento expuesto en la tragedia? Al espectador, pues los actores sólo dramatizan el proceso implicado en el $\pi \dot{\alpha} \theta \varepsilon ı \mu \dot{\alpha} \theta 0 \varsigma$. Así, por ejemplo, Agamenón debería de ser un alumno aventajado en este aprendizaje doloroso, si se tiene en cuenta la experiencia vivida desde que inició la campaña contra los troyanos y si tenemos en cuenta la interpretación de Lesky (2001) sobre este punto: "Obrando, cae el hombre en la culpa, toda culpa encuentra su expiación en el sufrimiento, pero el sufrimiento lleva al hombre a la comprensión y la comprensión al conocimiento (p. 157).

Sin embargo, contrariamente a lo esperado, resulta que lo trágico en sí le aguarda al rey en su palacio, a su regreso. Esto probaría que $\pi \dot{\alpha} \theta \varepsilon l \mu \dot{\alpha} \theta$ os es un proceso trágico por naturaleza, y no una experiencia que alecciona y ejercita al individuo.

Sin tener la intención de proponer una modificación en la disposición del texto griego, es posible tener una mejor comprensión del contenido, si se coloca la alabanza a Zeus como cierre de la párodos. Si, como hemos venido viendo, los acontecimientos de la guerra de Troya contados en esta parte sirven de prolegómenos para comprender la secuencia y el sentido de la Orestiada, entonces la naturaleza didáctica de la párodos se evidencia con claridad al disponer que sólo se aprende padeciendo el dolor, es decir, los acontecimientos de la guerra deberían de ser vistos y utilizados como un modo de aprender, pero sólo es un tópico más en la cadena de acontecimientos trágicos, una lección de la didáctica trágica. El dolor provocado a través de esa aventura bélica es un modo acerbo para entender el porqué del malestar trágico. Uno de los problemas en la inversión sugerida de las estrofas es que el final de la párodos da pie para la intervención de Clitemnestra, ${ }^{27}$ con lo cual también se cierra esta parte de la tragedia, por lo que para algunos estudiosos el mensaje contenido en $\pi \dot{\alpha} \theta \varepsilon \iota$ $\mu \dot{\alpha} \theta 0 \varsigma$ está dirigido a la reina argiva. Sin embargo, fuera de la observación técnica de que tales palabras dan la entrada al escenario a Clitemnestra, con lo que inicia propiamente la primera escena, ${ }^{28}$ consideramos que hay un claro encadenamiento de los tópicos tratados en la párodos, cuyas partes centrales son la descripción de algunos sucesos de la guerra de Troya, el sacrificio de Ifigenia y la conclusión contenida en $\pi \dot{\alpha} \theta \varepsilon \iota \mu \dot{\alpha} \theta \circ \varsigma$, lo que a su vez marca el sentido que recorre toda la trilogía.

En efecto, $\pi \dot{\alpha} \theta \varepsilon l \mu \dot{\alpha} \theta$ os involucra a todo el género humano y no sólo es una advertencia paremiológica dirigida específicamente a Clitemnestra, pues se trata de un proceso concreto mediante el cual se comprende qué es lo trágico. El mensaje del Coro no remite exclusivamente a los personajes centrales que están llamados de modo directo en la párodos: en primer lugar, el referente es Agamenón, pues es a él a quien se está esperando ya, una vez que se ha generado la expectación de que ha finalizado la guerra; en segundo lugar, la indicación a la reina argiva para que disipe la duda sobre el regreso de su marido marca un compás de espera y le imprime su dosis de dramatismo al recorrido de la párodos (vv. 228-263); y, más significativo aún, el mismo Coro no se puede sustraer a la sentencia del aprender sufriendo, pues él es el didáskalos que enseña la naturaleza de esta sentencia simplemente porque es el sujeto cognoscente por antonomasia. Por ello, se plantea que $\pi \dot{\alpha} \theta \varepsilon \iota$ $\mu \dot{\alpha} \theta \circ \varsigma$ tiene una implicación clara en el comprensión completa de la trilogía. Agamenón vuelve de la guerra triunfante, pero a pesar de los dolores vividos, no aprendió lo suficiente para prever y analizar la desgracia que se cernía sobre él, lo que lo llevó a cometer errores que son claros preámbulos de su muerte. Por su parte, Clitemnestra funciona como una Erinia sin mayor reflexión sobre el sentido del dolor, por lo que su ceguera la conduce también al fin de su propia existencia; y, por último, el Coro hace eco de la sabiduría que permitiría evitar la desgracia, pero aun cuando la fórmula parece simple, se comprueba, sin embargo, que $\pi \dot{\alpha} \theta \varepsilon \iota \mu \dot{\alpha} \theta_{\circ}$ contiene un dolor tal que el ser humano prefiere la renuncia al conocimiento, lo cual de cualquier modo no lo salva de caer en lo trágico. A diferencia de lo que sugieren Denniston y Page (1957) cuando indican que es la experiencia la que enseña al personaje (experientia docet, p. 85), consideramos al contrario que es en la inmersión de lo trágico como se aprende, pues el dolor y el saber van de la mano en la dinámica trágica del sujeto, de modo que lo aprendido sucede cuando el sufrimiento es una situación irrevocable. En todo caso, la meta última del conocimiento es un estado de dolor en el ser humano. 
El proceso del $\pi \dot{\alpha} \theta \varepsilon l \mu \dot{\alpha} \theta \circ \varsigma$ se explicaría así: a todo error (hamartía) sigue una tragedia: el crimen de Agamenón no sólo es la muerte de Ifigenia a través de sus manos, ${ }^{29}$ sino que el destino trágico que le esperaba en su palacio responde también a los hechos de la guerra en Troya, ${ }^{30}$ y además al sino que le marcaba trágicamente por ser descedendiente de Tántalo y, en consecuencia, ser parte de una herencia de asesinatos intrafamiliares a causa del poder otorgado por Zeus y definido por la $\tau \iota \mu \dot{\eta}$.

En suma, la interpretación poética de Ritsos al inicio de su Agamenón nos permite leer la párodos de la tragedia homónima de Esquilo desde la perspectiva del sinsentido de la guerra cuando esta concluye y lo que continúa enseguida es la desolación que provoca lo trágico. El magisterio de Esquilo fue comprendido por Ritsos como el punto en el que coinciden el deber impuesto por el destino y lo absurdo de las acciones que se ejecutan para tal finalidad; por principio, la obligación está marcada por la guerra, pues el triunfo de Agamenón sólo es un preámbulo irónico del fin que le acaece en su propia casa: el vencedor es vencido de un modo totalmente opuesto al heroísmo. El sujeto trágico, desde esta perspectiva, aprende mediante el sufrimiento que es necesario atravesar el conocimiento para probar y comprender lo que el deber le impone. La obligación que se perfila como parte del destino conduce al rey argivo a llevar acciones que lo van encaminando hacia su propia desgracia, creyendo que el acatamiento es una bifurcación en la que cualquier elección del camino conduce inexorablemente a la tragedia. Refiriéndose a Agamenón, Lesky (2001) afirma que "vemos al hombre de Esquilo en aquella apurada situación del destino que, sin embargo, no le exime de la propia responsabilidad” (p. 154). ¿Hasta qué punto se puede sostener esta visión cuando, como hemos visto, a Agamenón no le resta más que debatirse entre la obligación y la imposibilidad de modificar una decisión tomada por el destino imperioso? No hay voluntad en el hombre, sólo una obediencia a la voluntad de los dioses y a las acciones impuestas por el deber y no por el ser. Es aquí donde el poder y sus actos se tornan absurdos, pues Agamenón, rey de hombres, no puede gobernar las cuestiones más elementales que, al escaparse de su dominio, se tornan trágicamente irreversibles. Y quizá lo más doloroso para el hombre sea aprender que lo vivido siempre resultará absurdamente trágico, como veladamente lo reconoce el Agamenón de Ritsos:

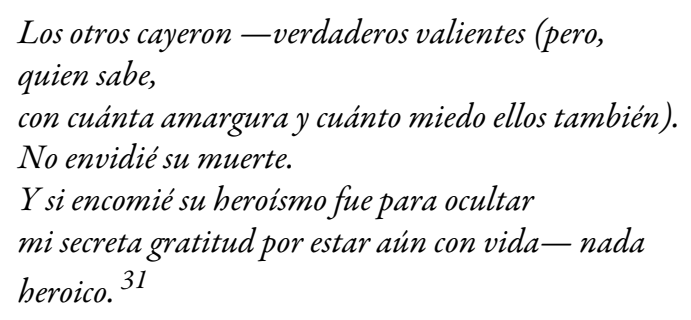

\section{ReFERENCIAS}

Bérard, V. (1924). Homère: L'Odyssée. Paris: Les Belles Lettres.

Bergson, L. (1982). Nochmals Artemis und Agamemnon. Hermes 110 (2), 137-145.

Denniston, J. D. y Page, D. (1957). Aeschylus: Agamemnon. Oxford: Clarendon Press.

Diehl, E. (1954). Anthologia lyrica graeca I. Leipzig-Berlin: Teubner.

Euben, J. P. (1982). Justice and the Oresteia. The American Political Science Review 76 (1), 22-33.

Frazer, J. G. (1921). Apollodorus: The Library, vols. Iy II. Cambridge: Cambridge University Press.

García Pérez, D. (2013). Esquilo: Prometeo encadenado. México: UNAM.

Goward, B. (2004). Telling Tragedy: Narrative Technique in Aeschylus, Sophocles and Euripides. London: Bristol Classical Press.

Iriarte Goñi, A. (1996). Democracia y tragedia: la era de Pericles. Madrid: Akal. 
Kaimio, M. (1970). The Chorus of Greek Drama within the Light of the Person and Number Used. Helsinki: Societas Scientiarum Fennica.

Lesky, A. (2001) La tragedia griega. Barcelona: El acantilado.

Mikalson, J. D. (1991). Honor Thy Gods: Popular Religion in Greek Tragedy. Chapel Hill: The University of North Caroline Press.

Monsacré, H. (1998). Homère: Iliade, IX-XVI. Paris: Les Belles Lettres.

Neitzel, H. (1979). Artemis und Agamemnon in der Parodos des Aischyleischen 'Agamemnon. Hermes 107(1), 10-32.

Nussbaum, M. (1985). Aeschylus and Practical Conflict. Ethics 95 (2), 233-267.

Pérez Vega, A. (1983). Ovidio: Metamorfosis. Barcelona: Bruguera.

Reeves, Ch. H. (1960). The Parodos of Agamemnon. CJ 55 (4), 161-171.

Ritsos, Y. (2018). Agamenón. Barcelona: El acantilado.

Rizzo, S. (1991). Pausania: Viaggio in Grecia. Milano: BUR.

Rodríguez, A. F. (1980). Lírica griega arcaica. Madrid: Gredos.

Roth, P. (1993). The Theme of Corrupted Xenia in Aeschylus' Oresteia. Mnemosyne 46 (1), 1-17.

Seaford, R. (2013). Aeschylus, Herakleitos and Pythagoreanism. En Cairms, D. (Ed.) Tragedy and Archaic Greek Thought (pp. 17-38). Wales: The Classical Pres of Wales.

Sommerstein, A. H. (2008) Aeschylus: Oresteia. Cambridge: Harvard University Press.

Torrano, J. (2013) Ésquilo: Orestéia I. Agamêmnon. Sâo Paulo: Iluminuras.

Vianello, P. (1986). Hesiodo: Los trabajos y los dias. México: UNAM.

\section{Notas}

1 Proyecto "Esquilo, Orestiada. Traducción, estudio filológico y de literatura comparada." Centro de Estudios Clásicos, IIFI, UNAM.

2 Ritsos (1909-1990) y Esquilo (c. 525-456 a.n.e.) tienen en común el haber sido poetas y soldados: el primero participó en la resistencia contra la invasión nazi (1941-1944) y el segundo, en las célebres batallas de Maratón y de Salamina contra los persas.

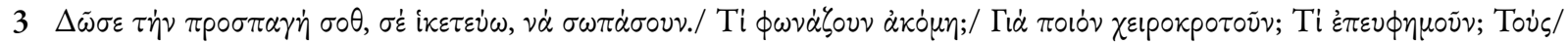

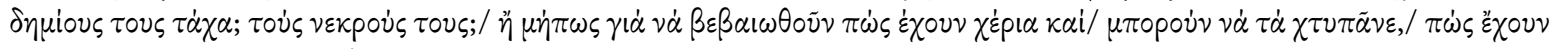

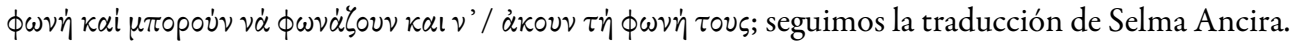

4 La mayoría de los estudiosos considera que la párodos abarca los versos 40-257. Sin embargo, Torrano (2013, p. 23), siguiendo a Aristóteles, Poética 52b, considera que "constituem o párodo somente os versos 40-103, anapésticos, en ritmo de marcha. Neste párodo, stricto senso, enquanto o coro caminha até a orquestra, completam-se as informações dadas no prólogo referentes ao tempo do drama, ao carácter da expedição contra Tróia, à personalidade do coro e às circunstâncias presentes da ação." Cf. Iriarte Goñi (1996, pp. 13-14).

5 Los mitos que componen la Orestiada se remontan al equívoco proceder de Tántalo, quien ofreció como comida a los dioses a su hijo Pélope. Esta acción puede leerse como un sacrificio a las divinidades, hecho que se repite, en cierto modo, en el sacrificio de Ifigenia. Es por ello que la alusión a la muerte de esta doncella ocupa un lugar central en la párodos del Agamenón, pues con este tópico se engarzan los hechos pasados y futuros en torno de la guerra de Troya. Cf. Pausanias, Epítome II 3; Píndaro, Olimpica I; Ovidio, Metamorfosis IV 404-411.

6 Cf. Bergson (1982, p. 143).

7 Se trata de una imagen metafórica que asimila al anciano con el niño y que remite al mito de la Esfinge y al célebre enigma que este monstruo le planteó a Edipo: ¿qué ser dotado de voz tiene cuatro pies, dos y tres?, refiriéndose con ello a la niñez, adultez y vejez del hombre. Cf. Apolodoro, Biblioteca III 5, 8.

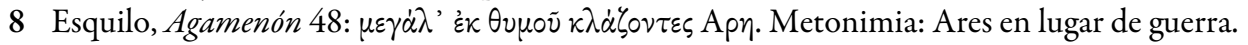

9 Tal imagen se representa de muy diversas expresiones poéticas. Cf. por ejemplo: Homero, Ilíada IV 313-316; VIII 112-114; XVIII 429-435; Odisea XI 195-196; XIII 59-62, XIII 210 ss., Mimnermo 2D.

10 En la sociedad formada por clanes, el crimen de sangre era una cuestión que hallaba sus soluciones en el estricto marco de las familias; los parientes más cercanos exigían una compensación al victimario y, en caso de no recibirla, iniciaban la persecución hasta matarlo. No había, pues, interés colectivo en el castigo de este delito. Sin embargo, el cambio social 
que significó el rompimiento de los lazos intrafamiliares de los clanes, en las monarquías del período heroico, supuso el traslado de un delito exclusivamente ligado a la parentela al espacio entero de la comunidad, como se observa ya en la democracia ateniense: las Erinias eran las deidades encargadas de perseguir y de castigar a los homicidas que violentaban el orden asentado desde el remoto tiempo de los clanes. Es en este punto donde se inserta el mito de los Atridas. Thomson (1970, pp. 52-53).

11 Egisto cobra venganza en Agamenón a causa de que su padre, Tiestes, fue engañado por Atreo al darle de comer a sus tres hijos Aglao, Calileonte y Orcómeno. Como hemos venido exponiendo, el tópico del sacrificio en la tragedia recorre un amplio camino, desde el binomio Tántalo-Pélope hasta llegar a Agamenón-Ifigenia: "birth and fruitfulnes have been murdered, the rich fecundity of the world struck down, and the gods dishonored by perverse sacrifice." Euben (1982, p. 25).

12 Seguimos la edición de Alan H. Sommerstein (2008). Las traducciones son nuestras.

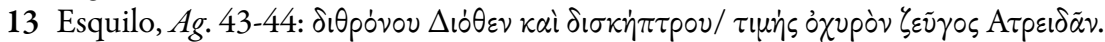

14 Cf. Milkalson (1991, p. 183). En el Prometeo encadenado se halla un ejemplo similar: la $\tau \nmid \eta \dot{n}$ del Titán rebelde es el fuego cuyas características implícitas guardan el doble sentido del regalo, es decir, las bondades y las desgracias que le acompañan cuando éste es entregado al ser humano. Dicha honra es compartida por Atenea, Hefesto y Prometeo, dioses del fuego; en los hombres esta $\tau \iota \mu \dot{~ s e ~ d i v e r s i f i c a ~ e n ~ l a s ~ d i f e r e n t e s ~ e n t r e ~ b i e n e s ~ y ~ m a l e s, ~ e s ~ d e c i r, ~ p a s a ~ a ~ s i g n i f i c a r ~ l a ~ h o n r a ~}$ del hombre en tanto que regalo que en adelante definirá su naturaleza. Sobre esto último, cf. García Pérez (2013, p. 120).

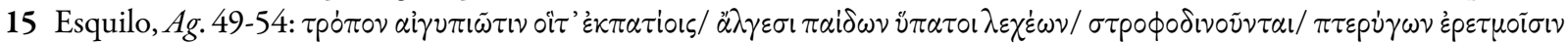

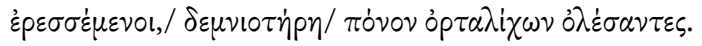

16 West (1979: 1). La imagen esquilea estaría inspirada en Homero, Ilíada XVI 428-429 y en Odisea XVI 216-218.

17 La observación al código de la hospitalidad es uno de los elementos temáticos principales en la definición de la díke en el Agamenón. Esta primera observación acerca del quebrantamiento de la hospitalidad se reitera en el primer estásimo (vv. 355-458); en el segundo estásimo (vv. 681-762), así como en diversas referencias a Zeus Xénios (vv. 61-62, 362, 748). Bergson (1982, pp. 138-139): "Nicht nur der Chor (an mehreren Stellen), sondern auch der Herold betont, daß Zeus Xenios die Rache an den Trojanern für Paris' Verbrechen fordert, und nicht nur Zeus, sondern auch die Moira

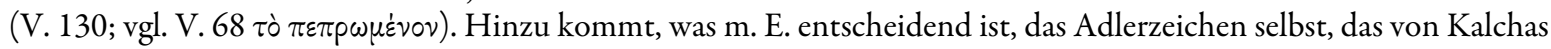

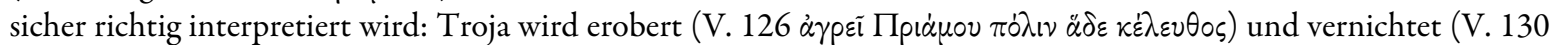

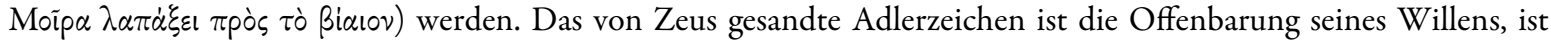
die $>>$ Antizipation des Schicksals $<<(. .$.$) ; es handelt sich um ein vaticinium agens, um die uralte Vorstellung von der$ Identität zwischen Voraussage und Schicksalserfullung." Cf. Roth (1993, p. 2-3); Torrano (2013, p. 24).

18 El estribillo tiene un sentido paremiológico. Se trata de un canto de duelo en honor de Lino, de quien existen diversas leyendas: fue hijo de Urania y Anfímaro, al que mató Apolo por ser su rival en el canto; otra versión vinculada con la música cuenta que fue hijo de Ismenio y que lo asesinó Heracles, su maestro. Cf. Pausanias, IX 29, 7-9.

19 Sobre la dificultad que ha implicado la interpretación de este pasaje, cf. Denniston y Page (1957, p. 80), Neitzel (1979, pp. 11-12).

20 Apolodoro, Epitome III 21.

21 Cf. Neitzel (1979, p. 10).

22 A lo largo del Agamenón hay una secuencia cronológica que coloca el pasado y el presente de modo reiterativo: los vv. 22 ss. refieren la expedición a Troya; más adelante, los vv. 264 ss. tocan el asunto de la caída de esta ciudad; los vv. 355 ss. hablan de Paris y la violación de la hospitalidad, lo que acarreó los males de Troya, al igual que en los vv. 681 ss. donde se alude a Helena también por este mismo acontecimiento. Todas estas situaciones descritas tienen como foco de la narración la espera y, finalmente, la llegada de Agamenón a su palacio. Cf. Goward (2004, p. 61).

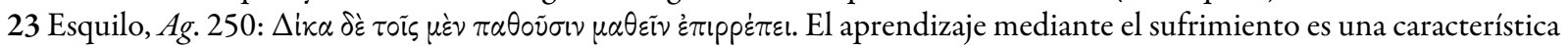
que define lo trágico. Este concepto va más allá de la anagnórisis, pues dicho aprendizaje o conocimiento se expresa como resultado de haber atravesado la experiencia trágica. Según Nussbaum (1985, p. 260): "The deep meaning of the proverbial pathei mathos, repeated both just before and just after the narrative of the slaughter of Iphigenia $(177,250)$, is that hard cases like these, if one allows oneself really to see and to experience them, may bring progress along with their sorrow, a progress that comes from an increase in self- knowledge and knowledge of the world. An honest effort to do justice to all aspects of a hard case, seeing and feeling it in all its conflicting many-sidedness, could enrich future deliberative efforts."

24 Cf. Seaford (2013, p. 31).

25 La diferencia entre un pensamiento recto y otro torcido está bien clara en el mito de Prometeo contado por Hesíodo, Los trabajos y los días 47-49. Este mismo tópico es retomado por Esquilo en el Prometeo encadenado, pero con un giro completo sobre el carácter positivo del conocimiento prometeico que dio lugar a la idea del progreso.

26 El Coro da voz a Agamenón, es decir, es el propio Atrida quien profiere estas palabras. Para Bergson (1982, p. 140), "Die

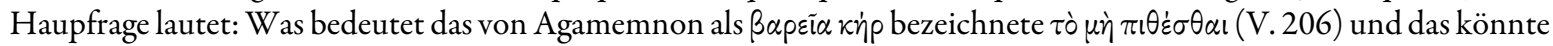
als Objekt dazu ergänzt werden? Nach der oben angeführten Interpretation der Verse 140-144, wonach Artemis das 


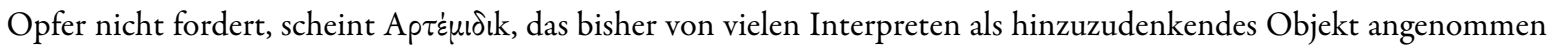
wurde, nicht mehr in Betracht kommen zu können".

27 Cf. Denniston y Page (1957, p. 92-93). Kaimio (1970, p. 45) ha hecho notar que Esquilo no concluye en ninguna otra parte coral la mención a un personaje que intervenga inmediatamente.

28 Persiste la duda acerca de si en el escenario se hallaba ya Clitemnestra desde que da inicio la párodos. Sobre este asunto, cf. Torrano (2003, p. 25).

29 Esquilo, Ag. 1521-1529; 1551-1559. Reeves (1960, p. 166): "On the one hand, most of the recent critics have inclined toward the view that Agamemnon, bent on pursuing a bloody and unjust war, in sacrificing his daughter Iphigenia incurred the full moral guilt of a heinous crime which he could presumably have somehow avoided, had he really wished to do so with the result that in falling by the hand of Clytemnestra he paid the penalty of simple justice under Zeus, a rationally beneficent god."

30 En esta misma párodos es explícito que la voluntad de Zeus, expresada a través de la ira que da el tono a la guerra, se aplica por igual a troyanos y a aqueos (Esquilo, $A g .60-71$ ), es decir, el sufrimiento no tiene una preferencia por un bando o por el otro, y por ello el triunfo de los Atridas sólo es un compás de espera para arribar, finalmente, a su destino trágico.

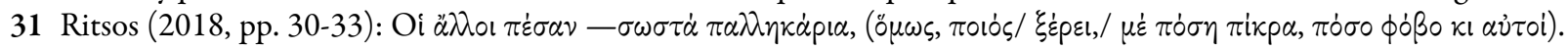

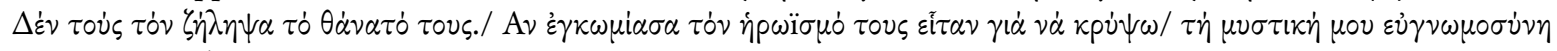

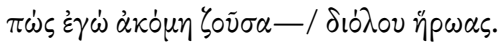

